OPEN ACCESS

Edited by:

Shaohua Hu,

Zhejiang University, China

Reviewed by:

Zhifen Liu,

First Hospital of Shanxi Medical

University, China

Rafael Silva

Pontifical Catholic University of Rio de

Janeiro, Brazil

*Correspondence:

Chuanyue Wang

wcyadyy@163.com

tThese authors have contributed equally to this work

Specialty section

This article was submitted to Mood and Anxiety Disorders,

a section of the journal

Frontiers in Psychiatry

Received: 27 May 2020

Accepted: 29 March 2021

Published: 28 April 2021

Citation:

Sun Z, Bo Q, Mao Z, Li F, He F, Pao C,

LiW, He Y, Ma X and Wang C (2021)

Reduced Plasma

Dopamine- $\beta$-Hydroxylase Activity Is Associated With the Severity of Bipolar Disorder: A Pilot Study.

Front. Psychiatry 12:566091.

doi: 10.3389/fpsyt.2021.566091

\section{Reduced Plasma}

\section{Dopamine- $\beta$-Hydroxylase Activity Is Associated With the Severity of Bipolar Disorder: A Pilot Study}

\author{
Zuoli Sun ${ }^{1,2+}$, Qijing Bo ${ }^{1,2+}$, Zhen Mao ${ }^{1,2}$, Feng $\mathrm{Li}^{1,2}$, Fan $\mathrm{He}^{1,2}$, Christine $\mathrm{Pao}^{3}$, Wenbiao $\mathrm{Li}^{1}$, \\ $\mathrm{Yi} \mathrm{He}{ }^{1,2}$, Xin $\mathrm{Ma}^{1,2}$ and Chuanyue Wang ${ }^{1,2 *}$ \\ ${ }^{1}$ The National Clinical Research Center for Mental Disorders and Beijing Key Laboratory of Mental Disorders and Beijing \\ Institute for Brain Disorders Center of Schizophrenia, Beijing Anding Hospital, Capital Medical University, Beijing, China, \\ ${ }^{2}$ Advanced Innovation Center for Human Brain Protection, Capital Medical University, Beijing, China, ${ }^{3}$ Department of \\ Psychiatry, University of North Carolina at Chapel Hill, Chapel Hill, NC, United States
}

Dopamine- $\beta$-hydroxylase $(\mathrm{D} \beta \mathrm{H})$ is an enzyme converting dopamine to norepinephrine, a key neurotransmitter in mood disorders, such as major depressive disorder (MDD) and bipolar disorder (BD). Due to overlapping symptomology of unipolar and bipolar depression, the present study attempted to explorer if the plasma $\mathrm{D} \beta \mathrm{H}$ activity could discriminate the depressive episodes of BD from MDD. The aim of this study was to compare the plasma $\mathrm{D} \beta \mathrm{H}$ activity among $\mathrm{MDD}$ patients $(n=104)$, BD patients ( $n=101)$, and healthy controls $(n=160)$. Clinical characteristics and cognitive function were assessed using the Young Mania Rating Scale (YMRS), Hamilton Depression Scale (HAM-D), Hamilton Anxiety Scale (HAM-A), Patient Health Questionnaire-9 (PHQ-9), and Repeatable Battery for the Assessment of Neuropsychological Status (RBANS). Our data showed a lower plasma $\mathrm{D} \beta \mathrm{H}$ activity in patients with $\mathrm{BD}$, not MDD, than that in controls. For the $\mathrm{BD}$ patients, the plasma $\mathrm{D} \beta \mathrm{H}$ activities were negatively correlated with HAM-D scores and HAM-A scores. However, there was no significant correlation between plasma $\mathrm{D} \beta \mathrm{H}$ activity and severity of depressive symptoms in MDD patients. No significant correlation between $\mathrm{D} \beta \mathrm{H}$ activities and cognitive assessments neither in $\mathrm{BD}$ nor in MDD patients. The present study provides evidence that BD is associated with decreased circulating $\mathrm{D} \beta \mathrm{H}$ activity.

Keywords: dopamine- $\beta$-hydroxylase, bipolar disorder, major depressive disorder, mood disorder, cognitive function

\section{INTRODUCTION}

Bipolar disorder (BD) is a complex and chronic psychiatric disease, with a prevalence to range from 0.5 to $5 \%$ in community-based samples $(1,2)$. BD is a disabling disease due to its early onset, severity and chronic nature although relatively rare (3). The important character of BD is the alternative episodes of mania and depression. However, major depressive disorder (MDD) and $\mathrm{BD}$ at depressive phase are similar in clinical manifestations, their overlapping symptomology makes difficult to differentiate BD at depressive phase from MDD (4). More importantly, the use of antidepressants in BD patients have limited efficacy even might increase the possible switch to 
manic episodes (5). Therefore, it is important to find biomarker to differentiate $\mathrm{BD}$ at depressive phase from $\mathrm{MDD}$, thereby to improve the therapeutic effect on mood disorders.

Unfortunately, the underlying mechanisms of BD and MDD have not yet been fully elucidated, while the monoaminergic theory has been regarded as the main cause of both MDD and $\mathrm{BD}(6-8)$. According to the monoamine hypothesis, monoamine neurotransmitters, including serotonin (5-HT), dopamine (DA), and norepinephrine (NE), have always been the key aspects in mood disorders. Although previous genetic, biological and pharmacological studies confirmed the important role of 5HT in MDD (7, 9), accumulating evidence suggested the contribution of dysregulated DA and NE transmission on both MDD and BD (10-12). DA and NE play an important role not only in cognitive function, but also in emotion regulation $(13,14)$. In general, depression was associated with reduced activity in the dopaminergic signaling system (15), whereas mania was associated with increased dopaminergic signaling (16). For example, depressive symptoms have been linked with hypodopaminergic transmission in the reward system (17), and dopaminergic stimulant agents augment the efficacy of antidepressants (18). On the other hand, hyperdopaminergic mice showed mania-like behaviors (19), and changed levels of 3-methoxy-4-hydroxyphenylglycol (MHPG, metabolites of NE) and homovanillic acid (HVA, metabolites of DA) were found in BD patients compared to controls $(10,20)$. Thus, the different changes of DA and NE transmission may contribute to explore the mechanism of MDD and BD.

Dopamine $\beta$-hydroxylase ( $\mathrm{D} \beta \mathrm{H}$ ) is the key regulatory enzyme required to synthesize NE from DA (21), and it is also important to maintain the brain $\mathrm{DA} / \mathrm{NE}$ balance. $\mathrm{D} \beta \mathrm{H}$ is located in both central (catecholamine vesicles) and peripheral systems (sympathetic nerves and adrenal medulla) $(22,23)$. Since D $\beta H$ can be released from catecholamine vesicles, the protein can be determined in the plasma or serum (21). Previous studies with mice deficient in $\mathrm{D} \beta \mathrm{H}$ demonstrated the role of $\mathrm{D} \beta \mathrm{H}$ in mood disorders. The birth rate of $\mathrm{DBH}$ gene knockout mice was much lower than wild-type mice, and the surviving mice almost died in the first week of life (24), suggesting the important role of $\mathrm{D} \beta \mathrm{H}$ in development and survival. Considering the important effect of NE and DA in cognition, several evidences indicated that $\mathrm{D} \beta \mathrm{H}$ might play a role in the cognitive defects in mental disorders (25-29), although $\mathrm{D} \beta \mathrm{H}$-deficient patients failed to display neurocognitive impairment $(30,31)$.

Abundant evidence has shown that low serum/plasma $\mathrm{D} \beta \mathrm{H}$ activity might be a risk factor for mental illness (21, 25, 27, 32). Furthermore, the genetic, biological and pharmacological studies indicated the important role of $\mathrm{D} \beta \mathrm{H}$ in $\mathrm{BD}$ and $\mathrm{MDD}$. The $D B H$ gene variants were proved to join in predicting individual differences in social and affective processing (33). Ates et al. indicated the mutated $\mathrm{DBH}$ gene increased the risk of BD (34). In addition, the serum $\mathrm{D} \beta \mathrm{H}$ activity was significant decreased in $\mathrm{BD}$ patients in depressive state compared with MDD patients (35), while it was lower in MDD patients than that in healthy controls (36-40). Interestingly, compared with drug-naive BD patients, serum $\mathrm{D} \beta \mathrm{H}$ activity was higher in lithium-treated $\mathrm{BD}$ patients (41). However, other studies showed the contrary results
$(42,43)$. Animal studies indicated stress increased expression of $\mathrm{D} \beta \mathrm{H}$ mRNA and protein in mood-related areas in the brain $(44,45)$. The contrary studies suggested the complex role of $\mathrm{D} \beta \mathrm{H}$ in patients with mood disorders, even between MDD patients and BD patients in depressive state.

Due to overlapping symptomology of unipolar and bipolar depression, the present study attempted to explorer if the plasma $\mathrm{D} \beta \mathrm{H}$ activity could discriminate the depressive episodes of $\mathrm{BD}$ from MDD. The aim of this study was to investigate whether plasma $\mathrm{D} \beta \mathrm{H}$ activity differs between: (i) $\mathrm{BD}$ patients and healthy controls (HCs), (ii) MDD patients and HCs, (iii) BD patients and MDD patients. The plasma $\mathrm{D} \beta \mathrm{H}$ activity was tested in individuals with three groups: BD patients, MDD patients and HCs. Furthermore, the associations of $\mathrm{D} \beta \mathrm{H}$ activity and phenotypes of patients were also assessed in this study.

\section{MATERIALS AND METHODS}

\section{Subjects}

Subjects were recruited from Beijing Anding Hospital (China) from September 2014 to September 2016. The ethics committee of Beijing Anding Hospital approved the research. All of the individuals provided written informed consent to participate in the present study after fully explaining the purpose and procedure. Male and female patients aged 16 to 60 years who met the Diagnostic and Statistical Manual of Mental Disorders, Fourth Edition (DSM-IV) criteria for MDD, or BD were recruited. All patients were screened using the Structured Clinical Interview for DSM-IV Axis I disorders-Patient Edition (SCID) by experienced psychiatrists. In the present study, all the patients with MDD were undergone depressive episodes, while the $\mathrm{BD}$ patients also with a current depressive episode were recruited.

The inclusion criteria of all patients were as follows: (1) aged 16 to 60 years; (2) formal education $\geq 9$ years; (3) total scores of Young Mania Rating Scale $(Y M R S) \leq 6$. The exclusion criteria of all patients were as follows: (1) comorbidity with other psychiatric disorders, such as schizophrenia; (2) electric convulsive therapy in recent 3 months; (3) were or had a history of substance dependence; (4) severe suicidal tendencies; (5) severe physical diseases, such as neurological diseases, cardiovascular disease, hepatic or renal diseases; (6) current pregnancy or breastfeeding.

The present study recruited gender-matched $\mathrm{HC}$ individuals with no history of psychosis or cognitive impairment. HCs underwent a psychiatric interview by experienced clinicians using the SCID to exclude psychiatric disorders. HCs were excluded when encounter the following situations: (1) had any lifetime DSM-IV psychiatric disorder; (2) had severe physical diseases, such as neurological diseases, cardiovascular disease, hepatic or renal diseases; (3) had a family history of psychiatric diseases; (4) were or had a history of substance dependence; (5) were current pregnancy or breastfeeding.

\section{Clinical Assessments}

Clinical assessments were administrated by experienced psychiatrists, who were blinded to participants. The patients were assessed with several clinical scales, including the Young 
Mania Rating Scale (YMRS) (46), Hamilton Depression Scale (HAM-D) (47), Hamilton Anxiety Scale (HAM-A) (47), and Patient Health Questionnaire-9 (PHQ-9) (48). In addition, the cognitive function of each participant was assessed with Wechsler Adult Intelligence Scale (brief form), Stroop's colorword test (49), and Repeatable Battery for the Assessment of Neuropsychological Status (RBANS) (50). Five aspects of the RBANS were evaluated, including attention, speech, visual span, immediate memory, and delayed memory.

\section{Plasma D $\beta H$ Activity Assay}

Peripheral blood from each individual was collected in this study. Plasma was harvested and stored at $-80{ }^{\circ} \mathrm{C}$ until they were used for the detection of $\mathrm{D} \beta \mathrm{H}$ activity. The $\mathrm{D} \beta \mathrm{H}$ activity was detected with the method reported from our laboratory (25), which was based on the enzymatic conversion of tyramine (substrate) to octopamine by $\mathrm{D} \beta \mathrm{H}$. Briefly, the reaction mixture $(100 \mu \mathrm{L})$ was composed of $1 \mathrm{M} \mathrm{CH} 3 \mathrm{COONa}$ buffer $(\mathrm{pH}=5.0), 0.2 \mathrm{M}$ sodium fumarate, $0.2 \mathrm{M}$ ascorbic acid, $1,500 \mathrm{U}$ catalase, $0.2 \mathrm{M}$ tyramine hydrochloride, $0.02 \mathrm{M}$ pargyline, $0.2 \mathrm{M}$ N-ethylmaleimide, pure water and plasma $(5 \mu \mathrm{L})$. After being incubated at $37^{\circ} \mathrm{C}$ for $1 \mathrm{~h}$, the reaction was stopped by adding $20 \% \mathrm{HClO} 4(20 \mu \mathrm{L})$. The supernatant was transferred to high performance liquid chromatography (HPLC) system after centrifugation (2,000 $\mathrm{rpm}$ ) for $10 \mathrm{~min}$. Octopamine concentration was measured by column-switching, reverse phase HPLC system (U3000, Thermo Fisher Scientific, Waltham, MA, USA), with electrochemical detection. Electrodes 1 and 2 of the cell were set at +700 and $-320 \mathrm{mV}$, respectively. Synephrine was used as internal standard. Octopamine and synephrine were separated by a $5 \mu \mathrm{m}$ particle size reversed-phase SB-C18 analytical column $(2.1 \times 150 \mathrm{~mm})$ obtained from Agilent Technologies (Santa Clara, CA, USA). The mobile phase was composed of $50.9 \mathrm{mM}$ potassium acetate, $14.3 \mathrm{mM}$ citric acid, $1.38 \mathrm{mM}$ 1-octanesulfonic acid, and 9.5\% methanol $(\mathrm{v} / \mathrm{v})$. All chemicals were purchased from SigmaAldrich (St. Louis, MO, USA).

\section{Statistical Analysis}

The data were analyzed using SPSS with version 20.0 (SPSS Inc., Chicago, IL, USA). Demographic and clinical characteristics were compared among three groups using $\chi^{2}$-tests or oneway analysis of variance (ANOVA). Consideration of the significant difference in age, the covariance analysis was used to compare the continuous variables, including plasma $\mathrm{D} \beta \mathrm{H}$ activities among groups with age as a covariate. On the other hand, the multivariate logistic regression analysis was used to evaluate the associations between discontinuous variable, including sex, family history, current state of illness, and mood disorders susceptibility with adjustment for age. Twoway ANOVA was used to evaluate the interaction effects between groups and gender, or compare the plasma $\mathrm{D} \beta \mathrm{H}$ activity in patients with different episodes. The comparison of plasma $\mathrm{D} \beta \mathrm{H}$ activity in patients with different kinds of drugs was also used with two-way ANOVA. In order to minimize the bias of demographic data on the analysis, the partial correlation was used to analyze the association of $\mathrm{D} \beta \mathrm{H}$ activity and clinical and cognitive assessments, with age, education, duration of illness and first onset age as covariates. The level of significance was set at $p<0.05$. However, the corrected $p$-value was set at 0.0167 considering the multiple testing of cognitive functions of the patients in the partial correlation analysis.

\section{RESULTS}

\section{Demographic and Clinical Characteristics}

A total of 389 individuals were initially screened for this study, and 24 (14 in MDD group, six in BD group, and four in control group) were excluded due to the declining to participate, not drawing blood or not meeting the inclusion criteria. Ultimately, the study population comprised of 104 MDD patients, 101 BD patients and $160 \mathrm{HCs}$. Although more than $90 \%$ patients completed all the clinical and cognitive assessments, only 116 HCs completed all the clinical assessments. The comparison of demographics and clinical characters among these three groups is shown in Table 1. Notably, there was a significant difference in age among groups $(F=6.795, p=0.001)$. Significant differences in the YMRS, HAM-D, and HAM-A total scores were found among three groups. More concretely, the HAM-D, HAM-A, and PHQ-9 scores were significantly increased in MDD or BD patients compared to HCs. However, the YMRS scores were higher in BD patients than MDD patients or HCs. Furthermore, these differences still exist after covariance analysis controlling for age (Table 1). In addition, according to the assessments of intelligence quotient (IQ), RBANS, and Stroop's tests, the MDD or BD patients showed significant deficits in cognitive function.

\section{Plasma D $\beta$ H Activity}

The average plasma $\mathrm{D} \beta \mathrm{H}$ activity in each group was shown in Figure 1 (the value was $17.31 \pm 11.85$ in HCs, $15.77 \pm 11.19$ in MDD patients, $13.49 \pm 7.56$ in $\mathrm{BD}$ patients). Covariance analysis (controlling for age) showed a significant decrease in plasma $\mathrm{D} \beta \mathrm{H}$ activity in $\mathrm{BD}$ patients compared to $\mathrm{HCs}(p=0.005)$. However, there was no significant difference in $\mathrm{D} \beta \mathrm{H}$ activity between MDD patients and HCs $(p=0.634)$. It should be noted that no significant difference in plasma $\mathrm{D} \beta \mathrm{H}$ activity was found between BD and MDD patients $(p=0.245)$.

In addition, we also analyzed the sex difference in plasma $\mathrm{D} \beta \mathrm{H}$ activity among three groups. No significant difference in plasma $\mathrm{D} \beta \mathrm{H}$ activity was found between males and females in these three groups (Figure 1B, $F=0.830, p=0.363$ ). Figures $1 C, D$ showed there was no significant association in plasma $\mathrm{D} \beta \mathrm{H}$ activities with age in each group (all $p>0.05$ ).

In order to exclude confounding factors, the patients were divided into first-episode and multi-episode patients (Figure 2). Only $10 \%$ patients $(n=10)$ were in first-episode in $\mathrm{BD}$, while this ratio was $38 \%(n=40)$ in MDD. Though there was no significant difference in plasma $\mathrm{D} \beta \mathrm{H}$ activity between firstepisode and multi-episode patients, the multi-episode patients showed a decrease trend compared with first-episode patients in both MDD (14.45 \pm 8.96 and $17.87 \pm 13.91$, respectively) and BD $(13.32 \pm 7.35$ and $15.10 \pm 9.66$, respectively). 
TABLE 1 | Demographics and other characteristics in three groups.

\begin{tabular}{|c|c|c|c|c|c|c|}
\hline & $\mathrm{HC}$ & MDD & BD & $\mathbf{F}$ & $p$ & $p_{\text {Covariance }}$ \\
\hline \multicolumn{7}{|l|}{ General characteristics } \\
\hline$n$ & 160 & 104 & 101 & & & \\
\hline Gender (male/female) & $80 / 80$ & $54 / 50$ & $62 / 39$ & $3.413^{a}$ & 0.182 & $0.121^{\mathrm{c}}$ \\
\hline Age (years) & $30.42 \pm 9.21$ & $34.77 \pm 11.13$ & $30.48 \pm 10.40$ & 6.795 & 0.001 & NA \\
\hline Education (years) & $13.77 \pm 3.17$ & $13.06 \pm 3.07$ & $13.09 \pm 3.13$ & 1.826 & 0.163 & 0.200 \\
\hline Duration of Illness (months) & NA & $67.75 \pm 69.83$ & $86.90 \pm 73.72$ & 3.647 & 0.058 & 0.002 \\
\hline First onset age & NA & $29.59 \pm 11.25$ & $23.49 \pm 9.25$ & 17.933 & $<0.001$ & 0.002 \\
\hline Family history (yes) & NA & 26 & 32 & $1.101^{a}$ & 0.294 & $0.238^{c}$ \\
\hline Type of first episode (depression/mania) & NA & NA & $75 / 26$ & & & \\
\hline Current state (remission/episodes) & NA & $48 / 56$ & $58 / 43$ & $2.84^{\mathrm{a}}$ & 0.096 & $0.067^{c}$ \\
\hline \multicolumn{7}{|l|}{ Medication (treated/untreated) } \\
\hline Mood stabilizers & NA & $3 / 101$ & $71 / 30$ & & & \\
\hline Antipsychotics & NA & $20 / 84$ & $63 / 38$ & & & \\
\hline Antidepressants & NA & $79 / 25$ & $27 / 74$ & & & \\
\hline \multicolumn{7}{|l|}{ Symptom assessment } \\
\hline YMRS & $1.13 \pm 2.13$ & $0.88 \pm 1.84$ & $3.27 \pm 6.02$ & 11.358 & $<0.001$ & $<0.001$ \\
\hline HAM-D & $0.40 \pm 1.13$ & $11.34 \pm 8.95$ & $8.92 \pm 9.06$ & 53.776 & $<0.001$ & $<0.001$ \\
\hline HAM-A & $0.42 \pm 1.09$ & $10.82 \pm 9.46$ & $7.94 \pm 8.40$ & 47.699 & $<0.001$ & $<0.001$ \\
\hline PHQ-9 & $3.36 \pm 6.02$ & $10.39 \pm 7.55$ & $7.57 \pm 7.38$ & 17.634 & $<0.001$ & $<0.001$ \\
\hline \multicolumn{7}{|l|}{ Cognitive assessment } \\
\hline IQ & $108.42 \pm 17.46$ & $100.69 \pm 16.32$ & $98.74 \pm 13.11$ & 9.715 & $<0.001$ & $<0.001$ \\
\hline \multicolumn{7}{|l|}{ RBANS } \\
\hline Attention & $108.16 \pm 14.54$ & $102.05 \pm 18.57$ & $101.53 \pm 14.11$ & 4.878 & 0.008 & 0.001 \\
\hline Speech & $98.14 \pm 18.65$ & $90.42 \pm 14.56$ & $85.37 \pm 14.63$ & 14.857 & $<0.001$ & $<0.001$ \\
\hline Visual span & $100.65 \pm 17.76$ & $96.98 \pm 17.09$ & $98.18 \pm 15.70$ & 1.127 & 0.325 & 0.229 \\
\hline Immediate memory & $91.14 \pm 18.06$ & $83.42 \pm 20.09$ & $80.22 \pm 17.09$ & 8.431 & $<0.001$ & $<0.001$ \\
\hline Delayed memory & $93.85 \pm 13.24$ & $85.59 \pm 19.15$ & $83.58 \pm 15.16$ & 10.383 & $<0.001$ & $<0.001$ \\
\hline Total scores & $97.27 \pm 15.54$ & $88.92 \pm 17.64$ & $85.82 \pm 11.34$ & 14.523 & $<0.001$ & $<0.001$ \\
\hline \multicolumn{7}{|l|}{ Stroop } \\
\hline Single word time & $15.49 \pm 5.02$ & $17.24 \pm 6.12$ & $17.76 \pm 5.42$ & 4.139 & 0.017 & 0.001 \\
\hline Monochromatic time & $20.17 \pm 6.28$ & $24.03 \pm 9.81$ & $26.74 \pm 11.12$ & 11.298 & $<0.001$ & $<0.001$ \\
\hline Double words time & $19.20 \pm 8.24$ & $21.30 \pm 10.09$ & $23.55 \pm 10.61$ & 4.558 & 0.011 & $<0.001$ \\
\hline Double color time & $36.64 \pm 12.11$ & $41.70 \pm 15.13$ & $44.79 \pm 16.56$ & 7.043 & 0.001 & $<0.001$ \\
\hline
\end{tabular}

Values represent mean $\pm S . D$.

${ }^{a}$ means $\chi^{2}$ test. ${ }^{C}$ means multivariate logistic regression analysis.

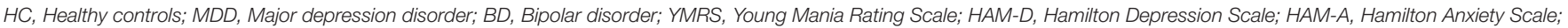
PHQ-9, Patient Health Questionnaire-9; IQ, Intelligence quotient; RBANS, Repeatable Battery for the Assessment of Neuropsychological Status.

\section{Associations of Plasma D $\beta H$ Activity and Clinical Variables}

No significant associations were found between $\mathrm{D} \beta \mathrm{H}$ activities and clinical assessments or cognitive function in MDD patients (Table 2, all $p>0.05$ ). However, significant negative correlations were found between $\mathrm{D} \beta \mathrm{H}$ activities and HAM-D scores $(r=$ $-0.234, p=0.021)$, or HAM-A scores $(r=-0.201, p=$ 0.041 ) in BD patients (Table 3, Figure 3). Nevertheless, plasma $\mathrm{D} \beta \mathrm{H}$ activities showed no significant correlation with cognitive assessments in BD patients (all $p>0.0167$ ).

\section{Discussion}

In this study, we enrolled 365 subjects, including $104 \mathrm{MDD}$ patients, $101 \mathrm{BD}$ patients, and $160 \mathrm{HCs}$, to complete the plasma
$\mathrm{D} \beta \mathrm{H}$ activity assay and clinical assessments. Five findings were obtained in our study: (1) Patients with BD, not MDD, showed a significant decrease in plasma $\mathrm{D} \beta \mathrm{H}$ activities compared with HCs; (2) No significant differences in plasma $\mathrm{D} \beta \mathrm{H}$ activities were found between the BD and MDD patients; (3) Significant negative correlations were found between $\mathrm{D} \beta \mathrm{H}$ activity and mood-related assessments in BD patients; (4) There was no correlation between $\mathrm{D} \beta \mathrm{H}$ activity and cognitive function in $\mathrm{BD}$; (5) In contrast to $\mathrm{BD}$ patients, no correlations were found between $\mathrm{D} \beta \mathrm{H}$ activity and clinical symptoms or cognition in MDD patients.

In the present study, we found that the plasma $\mathrm{D} \beta \mathrm{H}$ activity was significantly lower in $\mathrm{BD}$ patients; this was in line with the previous studies in $\mathrm{BD}(37,41)$. It is interesting to note that 

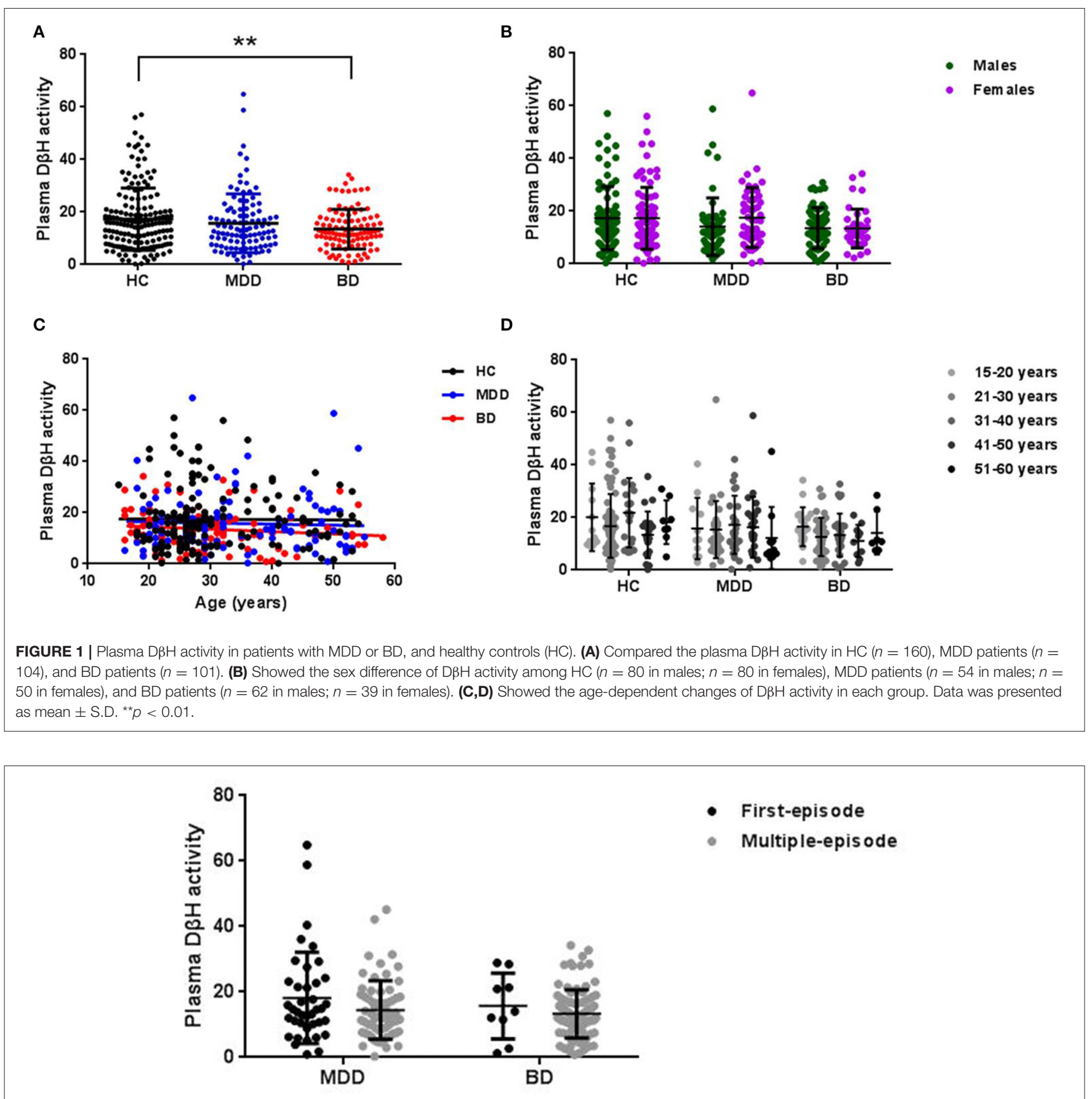

FIGURE 2 | Plasma D $\beta$ H activity in patients with different episodes, including first-episode (FE) and multi-episode (ME) in MDD and BD. There was no significant difference in $\mathrm{D} \beta \mathrm{H}$ activity in patients with different episodes in neither $\mathrm{MDD}(n=40$ in FE; $n=64$ in ME) nor $\mathrm{BD}(n=10$ in FE; $n=91$ in ME) groups. Data was presented as mean \pm S.D.

we also found no significant difference in plasma $\mathrm{D} \beta \mathrm{H}$ activity between $\mathrm{BD}$ and MDD patients. This may be due to the similarity of biological mechanisms and phenotypes between $\mathrm{BD}$ and $\mathrm{MDD}$ $(30,33)$. In addition, the $\mathrm{D} \beta \mathrm{H}$ product, $\mathrm{NE}$ also showed similar changes in $\mathrm{BD}$ and $\mathrm{MDD}(20,51-53)$. For example, NE was used as a stress factor to induced depression in several studies $(54,55)$, while stress was also a major risk factor of BD (56). Interestingly, there is report showed CSF NE concentration increased while DA levels decreased in rats after stress (57). The decrease of $\mathrm{D} \beta \mathrm{H}$ activity may be one of the reasons for the alteration in NE/DA imbalance. The studies of animal models of depression or mania proved the changes in NE system $(1,3,58-61)$. Furthermore, the 
TABLE 2 | Associations between plasma D $\beta H$ activity and clinical or cognitive assessments in patients with MDD.

\begin{tabular}{lccc}
\hline & $\boldsymbol{N}$ & $\mathbf{r}$ & $\boldsymbol{p}$ \\
\hline Symptom assessment & & & \\
HAM-D & 104 & 0.059 & 0.559 \\
HAM-A & 104 & -0.165 & 0.101 \\
PHQ-9 & 54 & -0.114 & 0.261 \\
Cognitive assessment & & & \\
IQ & 98 & -0.083 & 0.427 \\
RBANS & 97 & -0.066 & 0.531 \\
Stroop & & & 0.159 \\
Single Word Time & 93 & 0.151 & 0.429 \\
Monochromatic Time & 92 & -0.085 & 0.822 \\
Double Words Time & 92 & 0.024 & 0.588 \\
Double Color Time & 91 & -0.059 & \\
\hline
\end{tabular}

MDD, Major depression disorder; HAM-D, Hamilton Depression Scale; HAM-A, Hamilton Anxiety Scale; PHQ-9, Patient Health Questionnaire-9; IQ, Intelligence quotient; RBANS, Repeatable Battery for the Assessment of Neuropsychological Status.

TABLE 3 | Associations between plasma D $\beta H$ activity and clinical or cognitive assessments in patients with BD.

\begin{tabular}{lccc}
\hline & $\boldsymbol{N}$ & $\mathbf{r}$ & $\boldsymbol{p}$ \\
\hline Symptom assessment & & & \\
HAM-D & 101 & -0.234 & 0.021 \\
HAM-A & 101 & -0.201 & 0.041 \\
PHQ-9 & 69 & -0.105 & 0.304 \\
Cognitive assessment & & & \\
IQ & 97 & 0.203 & 0.051 \\
RBANS & 97 & 0.103 & 0.326 \\
Stroop & & & \\
Single Word Time & 94 & -0.109 & 0.308 \\
Monochromatic Time & 95 & -0.17 & 0.107 \\
Double Words Time & 95 & -0.053 & 0.618 \\
Double Color Time & 95 & -0.023 & 0.831 \\
\hline
\end{tabular}

BD, Bipolar disorder; HAM-D, Hamilton Depression Scale; HAM-A, Hamilton Anxiety Scale; PHQ-9, Patient Health Questionnaire-9; IQ, Intelligence quotient; RBANS, Repeatable Battery for the Assessment of Neuropsychological Status.

NE metabolism disruption also might be caused by the reduced $\mathrm{D} \beta \mathrm{H}$ in $\mathrm{BD}$. The metabolite of NE, MHPG in the circulating system was found higher in $\mathrm{BD}$ patients than controls $(4,35)$, but contrary results were also reported in several studies $(10,20)$. Interestingly, neuromodulation treatment on mood disorders was also associated with up-regulation of $\mathrm{NE}$ system or $\mathrm{D} \beta \mathrm{H}$ expression $(45,62,63)$. The inconstant results in plasma $D \beta H$ activity and NE levels in MDD or BD indicated the complex role of $\mathrm{D} \beta \mathrm{H}$ in mood disorders. One of the possible reasons for the contrary results might be the difference in detected tissues, such as the blood or the CSF; another reason might be different episodes with the BD patients, such as the manic or the remission state. In addition, the antidepressants, especially NE reuptake inhibitors improved the depressive symptoms directly through regulation of NE levels $(64,65)$. Together, the present study showed a decrease of plasma $\mathrm{D} \beta \mathrm{H}$ activity in $\mathrm{BD}$ patients, which may result in the reduced levels of NE to induced the symptoms of patients. Regrettably, plasma levels of NE were not detected in our study.

The main factor affecting $\mathrm{D} \beta \mathrm{H}$ activity is heredity. Numerous studies indicate that $D B H$ gene is a major quantitative trait locus that regulates blood and CSF D $\beta H$ activity $(25,66)$. Previous studies have reported several single nucleotide polymorphisms (SNPs) which correlate with plasma D $\beta H$ activity $(21,66-68)$. For example, a previous study reported -1021C > T (rs1611115) accounted for $35-52 \%$ of the variation in $\mathrm{D} \beta \mathrm{H}$ activity in African American, European American and Japanese (69); while our previous study showed the ratio was $12.6 \%$ in Chinese (25). However, few studies explored the association between $D B H$ gene polymorphisms and mood disorders. For example, one study showed that the $1603 \mathrm{C}>\mathrm{T}$ polymorphism of the $\mathrm{DBH}$ gene is associated with susceptibility to BD in a Turkish population (34). Zhou et al. reported that $D B H 5^{\prime}$ - Ins/Del polymorphism might be associated with susceptibility to MDD in a Chinese population (70). These results indicated the regulated role of $\mathrm{DBH}$ gene mutation in $\mathrm{D} \beta \mathrm{H}$ activity and its association with mood disorders (71).

Though evidence suggested low NE concentration was associated with MDD and BD, several studies showed that NE levels were different in patients between $\mathrm{MDD}$ and $\mathrm{BD}$. It is thought that high levels of NE resulted in mania, while low levels of NE led to depression (72). Wiste et al. compared the tyrosine hydroxylase ( $\mathrm{TH}$, the key enzyme of DA synthesis) immunoreactive cells in locus coeruleus (LC) among different subjects (73), and found that the $\mathrm{TH}$ immunoreactive cells in $\mathrm{LC}$ in $\mathrm{BD}$ patients were about half of those in controls or MDD patients, suggesting the lower NE transmission in $\mathrm{BD}$. In addition, neuronal damage in LC also emerged in BD, not MDD (74). However, no significant difference in plasma $\mathrm{D} \beta \mathrm{H}$ activity was found in our study. This result should be further confirmed due to several confusion factors in the present study. First, only $10 \%$ patients $(n=10)$ were in first-episode in $\mathrm{BD}$, while this ratio was $38 \%(n=40)$ in MDD in our study. Compared with firstepisode patients, multi-episode patients showed decrease trend in both $\mathrm{BD}$ and $\mathrm{MDD}$, suggesting the difference in $\mathrm{D} \beta \mathrm{H}$ activity might relate to the duration of disease. Second, several studies indicated the influence of antidepressants and mood stabilizers on $\mathrm{D} \beta \mathrm{H}$ activity $(41,75-77)$. In our study, the patients were treated with different psychotropics, including antidepressants (escitalopram, duloxetine), antipsychotics (olanzapine, aripiprazole and quetiapine), and mood stabilizers (lithium and valproic acid). For example, MDD patients were treated with different drugs (76\% antidepressants, 19\% antipsychotics and $3 \%$ mood stabilizers), meanwhile, $\mathrm{BD}$ patients were also treated with different kinds of drugs (70\% mood stabilizers, $62 \%$ antipsychotics, and $27 \%$ antidepressants). However, our study did not show the significant difference in patients treated with different kinds of psychotropics (Supplementary Figure 1, $p>0.05)$. Previous studies indicated that the antidepressive 

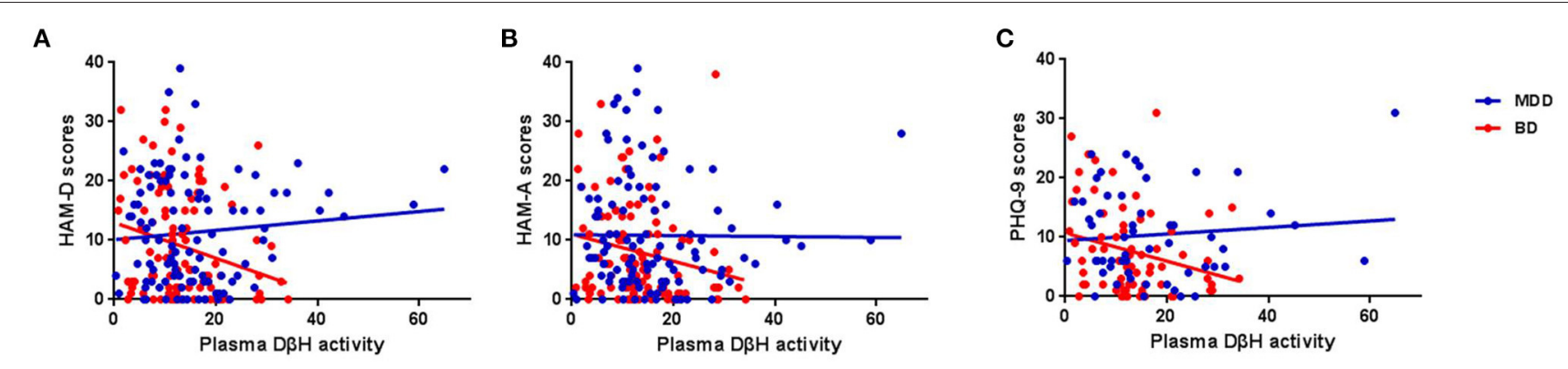

FIGURE 3 | Associations between plasma D $\beta H$ activity and clinical assessments in MDD and BD patients. (A-C) Showed the associations between plasma D $\beta H$ activity and Hamilton Depression Scale (HAM-D) scores, Hamilton Anxiety Scale (HAM-A) scores, and Patient Health Questionnaire-9 (PHQ-9) scores, respectively. Significant negative correlations were found between D $\beta \mathrm{H}$ activities and HAM-D scores $(r=-0.234, p=0.021)$, or HAM-A scores $(r=-0.201, p=0.041)$ in BD patients. However, no significant correlation was found between plasma D $\beta H$ activity and clinical assessments in MDD patients (all $p>0.05$ ).

effect of mood stabilizers and antidepressants might be partly mediated by $\mathrm{D} \beta \mathrm{H}$ and $\mathrm{NE}$ system $(75,78)$. Moreover, the $\mathrm{D} \beta \mathrm{H}$ activity was normalized during antidepressant therapy or mood stabilizers treatment $(40,41,79)$. However, our present study showed similar plasma $\mathrm{D} \beta \mathrm{H}$ activities in patients with different drug treatment groups, suggesting the similar regulation effect of different kinds of drugs. On the other hand, this inconsistency might also relate to the relative small sample size of patients and different medication duration (2-85 months).

To our knowledge, we firstly reported that plasma $\mathrm{D} \beta \mathrm{H}$ activity was associated with anxiety and depressive symptoms in BD. Previous studies showed low D $\beta H$ activity in CSF and serum in patients with mood disorders (37), and lower plasma $\mathrm{D} \beta \mathrm{H}$ activity in untreated patients with BD was found than that in controls and lithium-treated patients (41). However, no reports have shown a clear correlation between plasma/serum $\mathrm{D} \beta \mathrm{H}$ activity and severity of mood disorders. We found significant negative correlations between plasma $\mathrm{D} \beta \mathrm{H}$ activity and anxious and depressive symptoms in $\mathrm{BD}$. In other words, lower $\mathrm{D} \beta \mathrm{H}$ activity is associated with more severe anxious or depressive symptoms in BD. This confirmed the important role of plasma $\mathrm{D} \beta \mathrm{H}$ activity and monoamine neurotransmitter system in BD. However, no significant correlations were found between plasma $\mathrm{D} \beta \mathrm{H}$ activity and mania severity (YMRS scores) in our study. This might relate to the current state of the $\mathrm{BD}$ patients when recruited in the present study. About 57\% BD patients recruited in our study were in the remission stage, and the others were in the depressive stage (Table 1). It was a great pity that there was no BD patients in the manic state, while the YMRS scores were 3.27 ( $\mathrm{SD}=6.02)$. Further study should be conducted in the BD patients with manic state.

However, several limitations should be noted in this study. First, this study focused on the $\mathrm{D} \beta \mathrm{H}$ activity in MDD and $\mathrm{BD}$. However, other factors might also affect the dopaminergic transmission, such as polymorphisms of dopaminergic related genes as an endophenotype of MDD. Second, the three study groups, including patients with $\mathrm{MDD}$ or $\mathrm{BD}$ and $\mathrm{HCs}$, were not fully age-matched. These variables were corrected in the analysis. Third, a majority of patients were receiving antipsychotics and antidepressants, which have confounding effect to explore the role of $\mathrm{D} \beta \mathrm{H}$ in mood disorders. Finally, only $10 \%$ patients were in first-episode in BD, while the ratio was 38\% in MDD.

Taken together, this is a pilot study and shows a reduction of plasma $\mathrm{D} \beta \mathrm{H}$ activity as well as hypoactivity of the noradrenergic system in patients with $\mathrm{BD}$. The plasma $\mathrm{D} \beta \mathrm{H}$ activity is here proposed as a measure to evaluate the severity of BD.

\section{DATA AVAILABILITY STATEMENT}

The raw data supporting the conclusions of this article will be made available by the authors, without undue reservation.

\section{ETHICS STATEMENT}

The studies involving human participants were reviewed and approved by The ethics committee of Beijing Anding Hospital approved the research. Written informed consent to participate in this study was provided by the participants' legal guardian/next of kin.

\section{AUTHOR CONTRIBUTIONS}

CW, ZS, and QB obtained funding for this study. ZS and QB designed the research. ZS, QB, ZM, FL, WL, FH, and XM performed the experiments and statistical analysis. ZS, QB, YH, and CP wrote the manuscript. All authors contributed to the article and approved the submitted version.

\section{FUNDING}

This work was supported by Beijing Municipal Administration of Hospitals Clinical Medicine Development of Special Funding Support (ZYLX201807), National Natural Science Foundation of China (81801339), Beijing Science and Technology Commission (D121100005012002), Beijing Municipal Organization Department talents project (2016000021469G192), and Beijing Biobank of Clinical Resources-Mental Disorders (D131100005313011). 
No investigator benefited from participating in SUPPLEMENTARY MATERIAL

the study.

\section{ACKNOWLEDGMENTS}

The authors are grateful to all study participants in this study.

\section{REFERENCES}

1. Charlson F, van Ommeren M, Flaxman A, Cornett J, Whiteford H, Saxena S. New WHO prevalence estimates of mental disorders in conflict settings: a systematic review and meta-analysis. Lancet. (2019) 394:2408. doi: 10.1016/S0140-6736(19)30934-1

2. Merikangas KR, Jin R, He JP, Kessler RC, Lee S, Sampson NA, et al. Prevalence and correlates of bipolar spectrum disorder in the world mental health survey initiative. Arch Gen Psychiatry. (2011) 68:24151. doi: $10.1001 /$ archgenpsychiatry.2011.12

3. Ferrari AJ, Stockings E, Khoo JP, Erskine HE, Degenhardt L, Vos T, et al. The prevalence and burden of bipolar disorder: findings from the Global Burden of Disease Study 2013. Bipolar Disord. (2016) 18:440-50. doi: 10.1111/ bdi. 12423

4. Grande I, Berk M, Birmaher B, Vieta E. Bipolar disorder. Lancet. (2016) 387:1561-72. doi: 10.1016/S0140-6736(15)00241-X

5. Fornaro M, Anastasia A, Novello S, Fusco A, Solmi M, Monaco F, et al. Incidence, prevalence and clinical correlates of antidepressant-emergent mania in bipolar depression: a systematic review and meta-analysis. Bipolar Disord. (2018) 20:195-227. doi: 10.1111/bdi.12612

6. Schildkraut JJ. The catecholamine hypothesis of affective disorders: a review of supporting evidence. Am J Psychiatry. (1965) 122:50922. doi: 10.1176/ajp.122.5.509

7. Perez-Caballero L, Torres-Sanchez S, Romero-Lopez-Alberca C, GonzalezSaiz F, Mico JA, Berrocoso E. Monoaminergic system and depression. Cell Tissue Res. (2019) 377:107-13. doi: 10.1007/s00441-018-2978-8

8. Ashok AH, Marques TR, Jauhar S, Nour MM, Goodwin GM, Young AH, et al. The dopamine hypothesis of bipolar affective disorder: the state of the art and implications for treatment. Mol Psychiatry. (2017) 22:66679. doi: $10.1038 / \mathrm{mp} .2017 .16$

9. Kraus C, Castren E, Kasper S, Lanzenberger R. Serotonin and neuroplasticity - links between molecular, functional and structural pathophysiology in depression. Neurosci Biobehav Rev. (2017) 77:317-26. doi: 10.1016/j.neubiorev.2017.03.007

10. Kurita M, Nishino S, Numata Y, Okubo Y, Sato T. The noradrenaline metabolite MHPG is a candidate biomarker from the manic to the remission state in bipolar disorder I: a clinical naturalistic study. PLoS ONE. (2014) 9:e100634. doi: 10.1371/journal.pone.0100634

11. Belujon P, Grace AA. Dopamine system dysregulation in major depressive disorders. Int J Neuropsychopharmacol. (2017) 20:1036-46. doi: 10.1093/ijnp/pyx056

12. Nikolaus S, Mamlins E, Hautzel H, Muller HW. Acute anxiety disorder, major depressive disorder, bipolar disorder and schizophrenia are related to different patterns of nigrostriatal and mesolimbic dopamine dysfunction. Rev Neurosci. (2019) 30:381-426. doi: 10.1515/revneuro-2018-0037

13. Schwarz LA, Luo L. Organization of the locus coeruleus-norepinephrine system. Curr Biol. (2015) 25:R1051-6. doi: 10.1016/j.cub.2015.09.039

14. Cools R, Frobose M, Aarts E, Hofmans L. Dopamine and the motivation of cognitive control. Handb Clin Neurol. (2019) 163:123-43. doi: 10.1016/B978-0-12-804281-6.00007-0

15. Palucha-Poniewiera A, Podkowa K, Lenda T, Pilc A. The involvement of monoaminergic neurotransmission in the antidepressant-like action of scopolamine in the tail suspension test. Prog Neuropsychopharmacol Biol Psychiatry. (2017) 79(Pt B):155-61. doi: 10.1016/j.pnpbp.2017. 06.022

16. Milienne-Petiot M, Geyer MA, Arnt J, Young JW. Brexpiprazole reduces hyperactivity, impulsivity, and risk-preference behavior in mice with
The Supplementary Material for this article can be found online at: https://www.frontiersin.org/articles/10.3389/fpsyt. 2021.566091/full\#supplementary-material

Supplementary Figure 1 | Differences of plasma $D \beta H$ activity in patients treated with different kinds of psychotropics. Data was presented as mean \pm S.D.

dopamine transporter knockdown-a model of mania. Psychopharmacology (Berl). (2017) 234:1017-28. doi: 10.1007/s00213-017-4543-7

17. Clery-Melin ML, Jollant F, Gorwood P. Reward systems and cognitions in Major Depressive Disorder. CNS Spectr. (2019) 24:64-77. doi: 10.1017/S1092852918001335

18. Yan T, Greene M, Chang E, Houle CR, Tarbox MH, Broder MS. Impact of atypical antipsychotics as adjunctive therapy on psychiatric cost and utilization in patients with major depressive disorder. Clinicoecon Outcomes Res. (2020) 12:81-9. doi: 10.2147/CEOR.S231824

19. Kwiatkowski MA, Hellemann G, Sugar CA, Cope ZA, Minassian A, Perry W, et al. Dopamine transporter knockdown mice in the behavioral pattern monitor: a robust, reproducible model for mania-relevant behaviors. Pharmacol Biochem Behav. (2019) 178:42-50. doi: 10.1016/j.pbb.2017.12.007

20. Palsson E, Sellgren C, Ryden E, Kizza R, Pelanis A, Zetterberg H, et al. Cerebrospinal fluid monoamine metabolite profiles in bipolar disorder, ADHD, and controls. J Neural Transm (Vienna). (2017) 124:113543. doi: 10.1007/s00702-017-1746-3

21. Gonzalez-Lopez E, Vrana KE. Dopamine beta-hydroxylase and its genetic variants in human health and disease. J Neurochem. (2020) 152:15781. doi: $10.1111 /$ jnc. 14893

22. Catelas DN, Serrao MP, Soares-Da-Silva P. Effects of nepicastat upon dopamine-beta-hydroxylase activity and dopamine and norepinephrine levels in the rat left ventricle, kidney, and adrenal gland. Clin Exp Hypertens. (2020) 42:118-25. doi: 10.1080/10641963.2019.1583245

23. Schmidt K, Bari B, Ralle M, Washington-Hughes C, Muchenditsi A, Maxey E, et al. Localization of the locus coeruleus in the mouse brain. J Vis Exp. (2019) 145. doi: $10.3791 / 58652$

24. Thomas SA, Matsumoto AM, Palmiter RD. Noradrenaline is essential for mouse fetal development. Nature. (1995) 374:643-6. doi: 10.1038/374643a0

25. Sun Z, Ma Y, Li W, He J, Li J, Yang X, et al. Associations between the DBH gene, plasma dopamine beta-hydroxylase activity and cognitive measures in Han Chinese patients with schizophrenia. Schizophr Res. (2018) 193:5863. doi: $10.1016 /$ j.schres.2017.06.028

26. Shalev N, Vangkilde S, Neville MJ, Tunbridge EM, Nobre AC, Chechlacz M. Dissociable catecholaminergic modulation of visual attention: differential effects of catechol-O-methyltransferase and dopamine beta-hydroxylase genes on visual attention. Neuroscience. (2019) 412:175-89. doi: 10.1016/j.neuroscience.2019.05.068

27. Ji N, Shuai L, Chen Y, Liu L, Li HM, Li ZH, et al. Dopamine beta-hydroxylase gene associates with stroop color-word task performance in Han Chinese children with attention deficit/hyperactivity disorder. Am J Med Genet B Neuropsychiatr Genet. (2011) 156B:730-6. doi: 10.1002/ajmg.b.31215

28. Bensmann W, Zink N, Arning L, Beste C, Stock AK. The presynaptic regulation of dopamine and norepinephrine synthesis has dissociable effects on different kinds of cognitive conflicts. Mol Neurobiol. (2019) 56:8087100. doi: 10.1007/s12035-019-01664-z

29. Punchaichira TJ, Mukhopadhyay A, Kukshal P, Bhatia T, Deshpande SN, Thelma BK. Association of regulatory variants of dopamine betahydroxylase with cognition and tardive dyskinesia in schizophrenia subjects. J Psychopharmacol. (2020) 34:358-69. doi: 10.1177/0269881119895539

30. Jepma M, Deinum J, Asplund CL, Rombouts SA, Tamsma JT, Tjeerdema $\mathrm{N}$, et al. Neurocognitive function in dopamine-beta-hydroxylase deficiency. Neuropsychopharmacology. (2011) 36:1608-19. doi: 10.1038/npp.2011.42

31. Wassenberg T, Deinum J, van Ittersum FJ, Kamsteeg EJ, Pennings M, Verbeek $\mathrm{MM}$, et al. Clinical presentation and long-term follow-up of dopamine beta hydroxylase deficiency. J Inherit Metab Dis. (2020). doi: 10.1002/jimd.12321. [Epub ahead of print]. 
32. Cubells JF, Sun X, Li W, Bonsall RW, McGrath JA, Avramopoulos D, et al. Linkage analysis of plasma dopamine beta-hydroxylase activity in families of patients with schizophrenia. Hum Genet. (2011) 130:63543. doi: 10.1007/s00439-011-0989-6

33. Gong P, Liu J, Li S, Zhou X. Dopamine beta-hydroxylase gene modulates individuals' empathic ability. Soc Cogn Affect Neurosci. (2014) 9:13415. doi: $10.1093 /$ scan/nst122

34. Ates O, Celikel FC, Taycan SE, Sezer S, Karakus N. Association between $1603 \mathrm{C}>\mathrm{T}$ polymorphism of $\mathrm{DBH}$ gene and bipolar disorder in a Turkish population. Gene. (2013) 519:356-9. doi: 10.1016/j.gene.2013.01.031

35. Strandman E, Wetterberg L, Perris C, Ross SB. Serum dopaminebeta-hydroxylase in affective disorders. Neuropsychobiology. (1978) 4:24855. doi: 10.1159/000117637

36. Sapru MK, Rao BS, Channabasavanna SM. Serum dopamine-betahydroxylase activity in clinical subtypes of depression. Acta Psychiatr Scand. (1989) 80:474-8. doi: 10.1111/j.1600-0447.1989.tb03008.x

37. Meltzer HY, Tong C, Luchins DJ. Serum dopamine-beta-hydroxylase activity and lateral ventricular size in affective disorders and schizophrenia. Biol Psychiatry. (1984) 19:1395-402.

38. Meyers BS, Alexopoulos GS, Kakuma T, Tirumalasetti F, Gabriele M, Alpert S, et al. Decreased dopamine beta-hydroxylase activity in unipolar geriatric delusional depression. Biol Psychiatry. (1999) 45:448-52. doi: 10.1016/S0006-3223(98)00085-7

39. Cubells JF, Price LH, Meyers BS, Anderson GM, Zabetian CP, Alexopoulos GS, et al. Genotype-controlled analysis of plasma dopamine beta-hydroxylase activity in psychotic unipolar major depression. Biol Psychiatry. (2002) 51:358-64. doi: 10.1016/S0006-3223(01)01349-X

40. Paclt I, Koudelova J, Pacltova D, Kopeckova M. Dopamine beta hydroxylase (DBH) plasma activity in childhood mental disorders. Neuro Endocrinol Lett. (2009) 30:604-9.

41. Sofuoglu S, Dogan P, Kose K, Esel E, Basturk M, Oguz H, et al. Changes in platelet monoamine oxidase and plasma dopamine-beta-hydroxylase activities in lithium-treated bipolar patients. Psychiatry Res. (1995) 59:16570. doi: 10.1016/0165-1781(95)02631-2

42. Matuzas W, Meltzer HY, Uhlenhuth EH, Glass RM, Tong C. Plasma dopamine-beta-hydroxylase in depressed patients. Biol Psychiatry. (1982) 17:1415-24.

43. Markianos ES, Nystrom I, Reichel H, Matussek N. Serum dopaminebeta-hydroxylase in psychiatric patients and normals. Effect of d-amphetamine and haloperidol. Psychopharmacology. (1976) 50:259-67. doi: 10.1007/BF00426842

44. Fan Y, Chen P, Li Y, Cui K, Noel DM, Cummins ED, et al. Corticosterone administration up-regulated expression of norepinephrine transporter and dopamine beta-hydroxylase in rat locus coeruleus and its terminal regions. J Neurochem. (2014) 128:445-58. doi: 10.1111/jnc.12459

45. Stefanovic B, Spasojevic N, Jovanovic P, Dronjak S. Melatonin treatment affects changes in adrenal gene expression of catecholamine biosynthesizing enzymes and norepinephrine transporter in the rat model of chronic stress-induced depression. Can J Physiol Pharmacol. (2019) 97:68590. doi: 10.1139/cjpp-2018-0612

46. Xiao L, Gao Y, Zhang L, Chen P, Sun X. The relationship between cognitive function and quality of life in euthymic Chinese patients with bipolar disorder. Psychiatry Res. (2016) 246:427-31. doi: 10.1016/j.psychres.2016.10.026

47. Meng G, Ma X, Li L, Tan Y, Liu X, Liu X, et al. Predictors of early-onset post-ischemic stroke depression: a cross-sectional study. BMC Neurol. (2017) 17:199. doi: 10.1186/s12883-017-0980-5

48. Hu A, Xue Z, Mwansisya TE, Zhou A, Pu W, Chen X, et al. Major depressive disorder in hemodialysis patients in China. Asia Pac Psychiatry. (2015) 7:7884. doi: 10.1111/appy.12110

49. Chung YS, Kang DH, Shin NY, Yoo SY, Kwon JS. Deficit of theory of mind in individuals at ultra-high-risk for schizophrenia. Schizophr Res. (2008) 99:111-8. doi: 10.1016/j.schres.2007.11.012

50. Phillips R, Cheung YB, Collinson SL, Lim ML, Ling A, Feng L, et al. The equivalence and difference between the english and chinese language versions of the repeatable battery for the assessment of neuropsychological status. Clin Neuropsychol. (2015) 29(Suppl. 1):1-18. doi: 10.1080/13854046.2015.1034182

51. Yatham LN, Sossi V, Ding YS, Vafai N, Arumugham SS, Dhanoa T, et al. A positron emission tomography study of norepinephrine transporter occupancy and its correlation with symptom response in depressed patients treated with quetiapine XR. Int J Neuropsychopharmacol. (2018) 21:10813. doi: 10.1093/ijnp/pyx066

52. Borodovitsyna O, Joshi N, Chandler D. Persistent stress-induced neuroplastic changes in the locus coeruleus/norepinephrine system. Neural Plast. (2018) 2018:1892570. doi: 10.1155/2018/1892570

53. Wang B, Wang Y, Wu Q, Huang HP, Li S. Effects of alpha2A adrenoceptors on norepinephrine secretion from the locus coeruleus during chronic stress-induced depression. Front Neurosci. (2017) 11:243. doi: 10.3389/fnins.2017.00243

54. Gao J, Xi B, Chen K, Song R, Qin T, Xie J, et al. The stress hormone norepinephrine increases the growth and virulence of Aeromonas hydrophila. Microbiologyopen. (2018) 8:e00664. doi: 10.1002/ mbo3.664

55. Feng $\mathrm{Y}$, Feng Q, Yin $\mathrm{S}, \mathrm{Xu} \mathrm{X}$, Song $\mathrm{X}, \mathrm{Qu} \mathrm{H}$, et al. Stress adaptation disorders play a role in rat gestational diabetes with oxidative stress and glucose transporter-4 expression. Gynecol Endocrinol. (2020) 36:78690. doi: 10.1080/09513590.2019.1707797

56. Umeoka EHL, van Leeuwen JMC, Vinkers $\mathrm{CH}$, Joels $\mathrm{M}$. The role of stress in bipolar disorder. Curr Top Behav Neurosci. (2020) 48:2139. doi: 10.1007/7854_2020_151

57. Gu S, Jing L, Li Y, Huang JH, Wang F. Stress induced hormone and neuromodulator changes in menopausal depressive rats. Front Psychiatry. (2018) 9:253. doi: 10.3389/fpsyt.2018.00253

58. Soares-Cunha C, Coimbra B, Borges S, Domingues AV, Silva D, Sousa $\mathrm{N}$, et al. Mild prenatal stress causes emotional and brain structural modifications in rats of both sexes. Front Behav Neurosci. (2018) 12:129. doi: 10.3389/fnbeh.2018.00129

59. Siddique SA, Tamilselvan $\mathrm{T}$, Vishnupriya $\mathrm{M}$, Balamurugan E. Evaluation of neurotransmitter alterations in four distinct brain regions after Rapid Eye Movement Sleep Deprivation (REMSD) induced mania-like behaviour in swiss albino mice. Neurochem Res. (2018) 43:1171-81. doi: 10.1007/s11064-018-2533-8

60. Morilak DA, Barrera G, Echevarria DJ, Garcia AS, Hernandez A, Ma $\mathrm{S}$, et al. Role of brain norepinephrine in the behavioral response to stress. Prog Neuropsychopharmacol Biol Psychiatry. (2005) 29:121424. doi: 10.1016/j.pnpbp.2005.08.007

61. Meng L, Bai X, Zheng Y, Chen D, Zheng Y. Altered expression of norepinephrine transporter participate in hypertension and depression through regulated TNF-alpha and IL-6. Clin Exp Hypertens. (2019) 42:1819. doi: 10.1080/10641963.2019.1601205

62. Ventura-Bort C, Wirkner J, Genheimer H, Wendt J, Hamm AO, Weymar M. Effects of Transcutaneous Vagus Nerve Stimulation (tVNS) on the P300 and alpha-amylase level: a pilot study. Front Hum Neurosci. (2018) 12:202. doi: 10.3389/fnhum.2018.00202

63. Torres-Sanchez S, Perez-Caballero L, Mico JA, Celada P, Berrocoso E. Effect of deep brain stimulation of the ventromedial prefrontal cortex on the noradrenergic system in rats. Brain Stimul. (2018) 11:22230. doi: 10.1016/j.brs.2017.10.003

64. Ahmadimanesh M, Balarastaghi S, Rashedinia M, Yazdian-Robati R. A systematic review on the genotoxic effect of serotonin and norepinephrine reuptake inhibitors (SNRIs) antidepressants. Psychopharmacology. (2020) 237:1909-15. doi: 10.1007/s00213-020-05550-8

65. Dremencov E, el Mansari M, Blier P. Brain norepinephrine system as a target for antidepressant and mood stabilizing medications. Curr Drug Targets. (2009) 10:1061-8. doi: 10.2174/138945009789735165

66. Tang YL, Epstein MP, Anderson GM, Zabetian CP, Cubells JF. Genotypic and haplotypic associations of the $\mathrm{DBH}$ gene with plasma dopamine betahydroxylase activity in African Americans. Eur J Hum Genet. (2007) 15:87883. doi: 10.1038/sj.ejhg.5201838

67. Tang Y, Anderson GM, Zabetian CP, Kohnke MD, Cubells JF. Haplotypecontrolled analysis of the association of a non-synonymous single nucleotide polymorphism at $\mathrm{DBH}(+1603 \mathrm{C}->\mathrm{T})$ with plasma dopamine betahydroxylase activity. Am J Med Genet B Neuropsychiatr Genet. (2005) 139B:88-90. doi: 10.1002/ajmg.b.30220

68. Gonzalez-Lopez E, Kawasawa-Imamura Y, Zhang L, Huang X, Koltun $\mathrm{WA}$, Coates $\mathrm{MD}$, et al. A single nucleotide polymorphism in dopamine beta hydroxylase $(\mathrm{rs6271}(\mathrm{C}>\mathrm{T}))$ is over-represented in inflammatory bowel 
disease patients and reduces circulating enzyme. PLoS ONE. (2019) 14:e0210175. doi: 10.1371/journal.pone.0210175

69. Zabetian CP, Anderson GM, Buxbaum SG, Elston RC, Ichinose H, Nagatsu $\mathrm{T}$, et al. A quantitative-trait analysis of human plasma-dopamine betahydroxylase activity: evidence for a major functional polymorphism at the DBH locus. Am J Hum Genet. (2001) 68:515-22. doi: 10.1086/318198

70. Zhou Y, Wang J, He Y, Zhou J, Xi Q, Song X, et al. Association between dopamine beta-hydroxylase 19-bp insertion/deletion polymorphism and major depressive disorder. J Mol Neurosci. (2015) 55:367-71. doi: 10.1007/s12031-014-0339-y

71. Azadmarzabadi E, Haghighatfard A, Mohammadi A. Low resilience to stress is associated with candidate gene expression alterations in the dopaminergic signalling pathway. Psychogeriatrics. (2018) 18:190201. doi: $10.1111 /$ psyg. 12312

72. Maas JW, Huang Y. Noradrenergic function and depression, too much or too little? Can J Neurol Sci. (1980) 7:267-8. doi: 10.1017/S03171671000 23337

73. Wiste AK, Arango V, Ellis SP, Mann JJ, Underwood MD. Norepinephrine and serotonin imbalance in the locus coeruleus in bipolar disorder. Bipolar Disord. (2008) 10:349-59. doi: 10.1111/j.1399-5618.2007.00528.x

74. Bielau H, Brisch R, Bernard-Mittelstaedt J, Dobrowolny H, Gos T, Baumann $\mathrm{B}$, et al. Immunohistochemical evidence for impaired nitric oxide signaling of the locus coeruleus in bipolar disorder. Brain Res. (2012) 1459:919. doi: 10.1016/j.brainres.2012.04.022

75. Schank JR, Liles LC, Weinshenker D. Reduced anticonvulsant efficacy of valproic acid in dopamine beta-hydroxylase knockout mice. Epilepsy Res. (2005) 65:23-31. doi: 10.1016/j.eplepsyres.2005.03.010
76. Perlis RH, Adams DH, Fijal B, Sutton VK, Farmen M, Breier A, et al. Genetic association study of treatment response with olanzapine/fluoxetine combination or lamotrigine in bipolar I depression. J Clin Psychiatry. (2010) 71:599-605. doi: 10.4088/JCP.08m04632gre

77. Nciri R, Bourogaa E, Jbahi S, Allagui MS, Elfeki A, Vincent C, et al. Chronic neuroprotective effects of low concentration lithium on SH-SY5Y cells: possible involvement of stress proteins and gene expression. Neural Regen Res. (2014) 9:735-40. doi: 10.4103/1673-5374.131578

78. Cryan JF, Dalvi A, Jin SH, Hirsch BR, Lucki I, Thomas SA. Use of dopaminebeta-hydroxylase-deficient mice to determine the role of norepinephrine in the mechanism of action of antidepressant drugs. J Pharmacol Exp Ther (2001) 298:651-7.

79. Grabowska M, Schlegel-Zawadzka M, Papp M, Nowak G. Effect of imipramine treatment on plasma dopamine beta-hydroxylase activity in chronic mild stress in rats. Pol J Pharmacol. (2004) 56:825-9.

Conflict of Interest: The authors declare that the research was conducted in the absence of any commercial or financial relationships that could be construed as a potential conflict of interest.

Copyright (๑) 2021 Sun, Bo, Mao, Li, He, Pao, Li, He, Ma and Wang. This is an open-access article distributed under the terms of the Creative Commons Attribution License (CC BY). The use, distribution or reproduction in other forums is permitted, provided the original author(s) and the copyright owner(s) are credited and that the original publication in this journal is cited, in accordance with accepted academic practice. No use, distribution or reproduction is permitted which does not comply with these terms. 